\title{
ANÁLISE DOS ASPECTOS DIAGNÓSTICOS DO PASSIVO AMBIENTAL - LIXÃO, LOCALIZADO NA APA - LAGOAS DE GUARAJUBA, MUNICÍPIO DE CAMAÇARI - ESTADO DA BAHIA.
}

\author{
Fernando Ribeiro de Almeida \\ MBA em Perícia, Auditoria. e Gestão Ambiental \\ Roberto Ricardo Rachid Saab Barbosa Cunha \\ Observatório Urbano/OUERJ/UN-Habitat
}

\begin{abstract}
RESUMO
Avaliação do passivo ambiental gerado pela degradação do meio biótico e paisagístico, que vem ocorrendo na APA - Lagoas de Guarajuba, decorrente da destinação final inadequada do Resíduo Urbano dos condomínios e hotéis da localidade de Guarajuba, no Município de Camaçari - Estado da Bahia. Neste trabalho, foi feito exame diagnóstico dos fatores solo, ar e água, indicando os principais impactos ambientais, suas causas e conseqüências, gerados pelo desmatamento da restinga, destruição da flora e fauna, com o descarte e queima de resíduos sólidos nesta área de proteção ambiental. Também esta em evidência neste trabalho, a apresentação de solução para a mitigação desta ocorrência, passando pela análise crítica da alternativa de criação de fonte arrecadatória municipal, feita através de ações legislativas, que visem a criação e manutenção de unidades de conservação e preservação do meio ambiente.
\end{abstract}

PALAVRAS-CHAVE: Impactos ambientais, Proteção, Ações legislativas.

\begin{abstract}
Evaluation of the ambient liabilities generated by the degradation of the half biótico and paisagístico that comes occurring in the APA - Lagoons of Guarajuba, decurrent of inadequate the final destination of the Urban Residue of the condominiums and hotels of the locality of Guarajuba, in the City of Camaçari - Been of the Bahia. In this work, it was made disgnostic examination of the factors alone, air and water, having indicated the main ambient impacts, its causes and consequences, generated for thedeforestation of restinga, destruction of the flora and fauna, for discarding and burning of solid residues in this area of ambient protection. Also this in evidence in this work, the presentation of solutions for the mitigação of this occurrence, passing for the critical analysis of the alternative of creation of municipal arrecadatória source, made through legislative actions, that aim at the creation and maintenance of units of conservation and preservation of the environment.
\end{abstract}

Key word: Ambient impacts; Protection; Legislative actions. 


\section{INTRODUÇÃO}

Guarajuba apresenta uma das praias mais belas do Estado da Bahia, localizada no Município de Camaçari com a presença de condomínios e hotéis de luxo, distando $42 \mathrm{~km}$ de Salvador pela Linha Verde, sentido norte.

As praias desta área são bem freqüentadas, possuindo aparato turístico, mas também, convivendo com falta de estrutura sanitária e política adequada de ocupação do solo urbano. Guarajuba tem grande vocação turística, o que mais chama atenção, é que, a paisagem urbana convive com um cenário natural bem definido, produzindo grande beleza cênica, determinando assim, alta valorização econômica desta área. Estes fatos despertam a cobiça pelos terrenos e ensejam a especulação imobiliária, tendo como conseqüência principal, a expansão urbana desenfreada, sem condições adequadas para ocupação urbana. Este fator está acarretando sérios problemas ambientais, ameaçando potencialmente a Área de Proteção Ambiental - APA Lagoas de Guarajuba e concorre decisivamente para a geração do passivo ambiental objeto deste estudo.

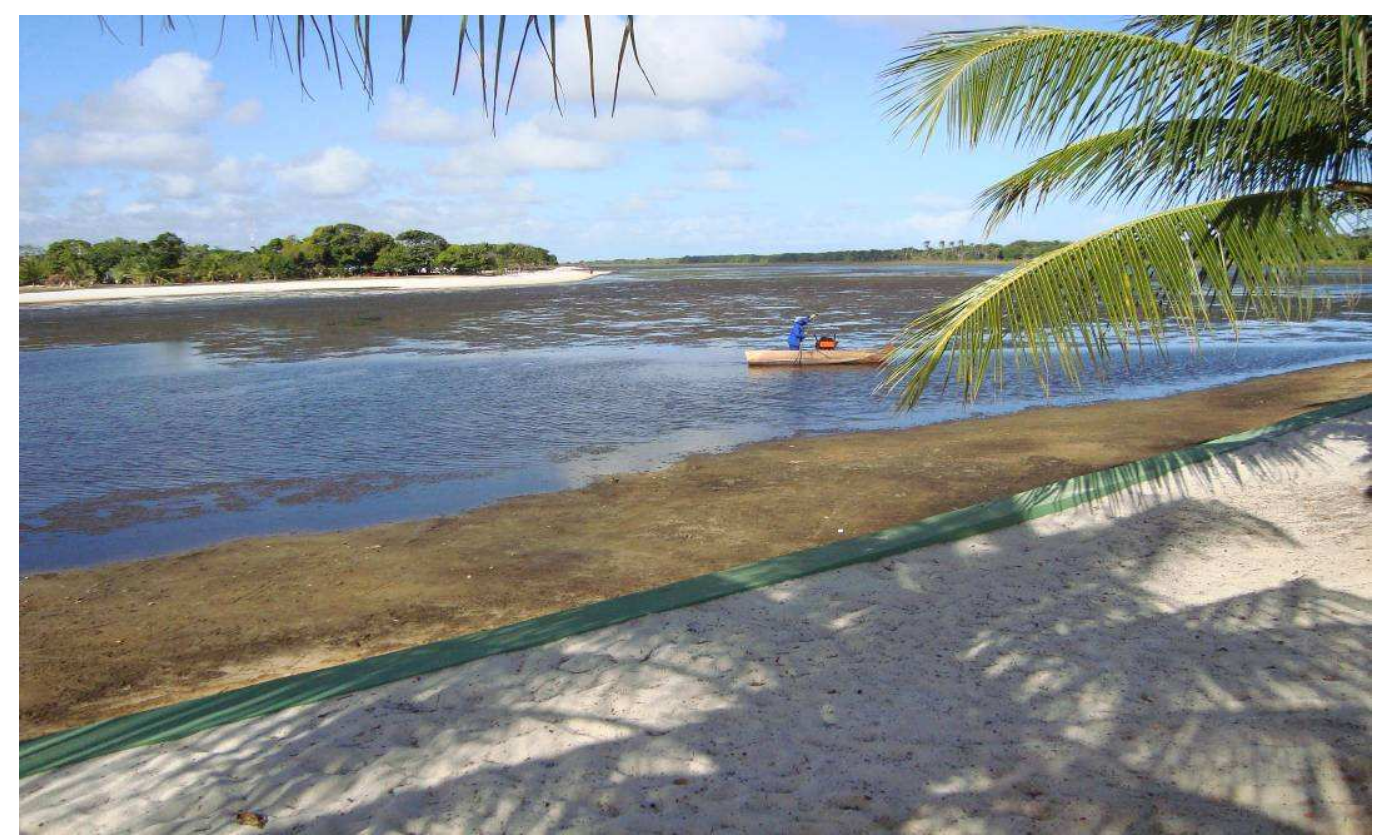

Figura 01 - Parte da lagoa que foi dragada, margeando condomínio de luxo. 


\section{CLASSIFICAÇÃO E DELIMITAÇÃO}

A classificação deste trabalho é um estudo de caso simplex da situação de ocorrência do "lixão", localizado na APA Lagoas de Guarajuba, nas imediações da praia de Guarajuba, no Município de Camaçari - Estado da Bahia.

\section{OBJETIVO E HIPÓTESE}

O principal objetivo deste trabalho é analisar a situação da APA Lagoas de Guarajuba, coexistindo com o passivo ambiental "lixão", passando pela avaliação crítica de possíveis soluções para a manutenção e conservação de unidades ambientais nos municípios, tendo como hipótese a seguinte afirmação: A APA Lagoas de Guarajuba está sendo pressionada pela especulação imobiliária, ocupação urbana desordenada e pela má administração dos resíduos sólidos ali produzidos, feita pela Prefeitura de Camaçari.

\section{METODOLOGIA E DESENVOLVIMENTO}

\section{Abordagem e procedimentos}

A abordagem utilizada foi hipotética dedutiva e os procedimentos adotados foram monográfico e estruturalista.

\section{Causas Remotas e Imediatas do Passivo}

O crescimento urbano desordenado, pressionado pela especulação imobiliária, que remotamente favoreceu a esta situação degradatória, além do Município de 
Camaçari, responsável pela coleta dos resíduos sólidos na localidade de Guarajuba, permitir que o lixo doméstico produzido pelos moradores dos diversos condomínios e hotéis localizados neste local, que também é de proteção ambiental, seja coletado e lançado diariamente a céu aberto, na forma de "lixão", sem nenhum controle, caracterizando-se em grave perturbação do meio ambiente.

\section{Ocorrência da Ação Impactante e Delimitação da APA Lagoas de Guarajuba}

Atualmente, cerca de 8 ton diárias de resíduos sólidos, produzidos por uma população média estimada de 10.000 pessoas, considerando $0.8 \mathrm{~kg}$ per capita por dia $^{1}$, são coletados, lançados e queimados a céu aberto de forma irregular, em área que foi desmatada no bioma da restinga, no interior da APA (Área de Proteção Ambiental) Lagoas de guarajuba, localizada na porção leste da estrada BA-099 (Estrada do Côco), tendo como limites, a Noroeste o Rio Pojuca e a Sudoeste o Rio Jacuípe.

Esta situação vem ocorrendo, há mais de uma década, sem que nenhuma providência tenha sido tomada pelos órgãos de controle ambiental do Município de Camaçari e do Estado da Bahia.

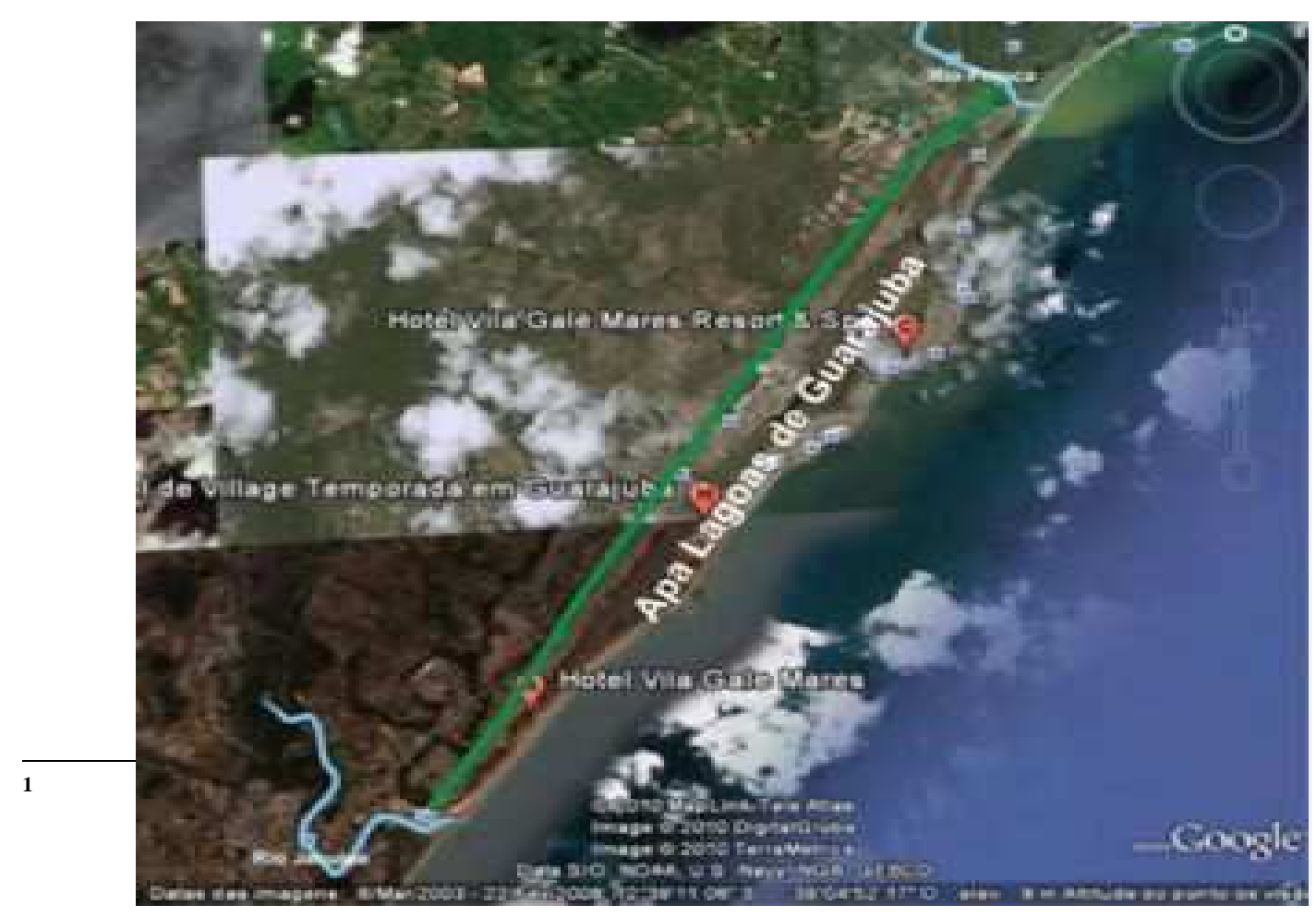


Figura 02 - Localização regional da APA - Lagoas de Guarajuba.

Escala aproximada: 1:240.000. ${ }^{2}$

\section{Caracterização Jurídica e Zoneamento da APA}

A designação da região como Área de Preservação Ambiental e a definição dos seus atributos naturais foi dada pela Resolução 387 de 27 de fevereiro de 1991 e o zoneamento para ocupação urbana, pela Resolução 388 de 12 e março de 1991, ambas do Conselho Estadual de Proteção Ambiental (CEPRAM-Ba). A resolução 387/1991, subdividiu a APA em quatro zonas. Quais sejam:

- Zona A - Compreende a porção de terreno, que tem como limite a noroeste a BA 099 (Estrada do Côco) e como limite sudeste a margem da lagoa de Guarajuba, excluída desta, a faixa de proteção de 30 metros em torno da lagoa;

- Zona B - Engloba a lagoa de Guarajuba, as ilhas arenosas que ocorrem no seu interior, que ainda apresentam vegetação nativa de porte arbóreo e a faixa de 30 metros nas margens da lagoa;

- Zona C - Inclui a área situada entre as margens sudeste da lagoa e a praia, excluindo desta, a faixa de 30 metros de proteção da lagoa e a faixa de 60 metros da praia;

- Zona D - Compreende a área de praia e a plataforma continental interna, incluindo os recifes de corais.

Também fica mencionado nesta Resolução, que as zonas $A$ e $C$, podem ter ocupação urbana, desde que, haja licença homologada pela CEPRAM. Entretanto, as zonas B e D, são áreas de preservação, sendo terminantemente proibidos, quaisquer tipos de ocupação, só uso cultural e recreativo. Vale lembrar, que a

\footnotetext{
2 A localização regional da APA e da área do passivo em estudo, foram feitas com fotografias de imagens de satélite retiradas do Google earth e as escalas determinadas através da medida das distancias reais no local.
} 
competência para julgar demandas envolvendo área de proteção Ambiental, é da Justiça Federal.

\section{Aspectos Geográficos e Biológicos da APA}

Compreende um complexo lacustre/lagunar entremeado entre as dunas, apresentando vegetação de restinga com extratos arbóreos, arbustivo e herbáceos.

A região propicia abrigo e alimento à fauna, em especial, as aves aquáticas.

A fauna constitui-se de espécies como tartarugas-marinha, crustáceos, insetos, aracnídeos e répteis. Fazem parte também, o sagüi (Callithrix sp), o peixe tucunaré e a raposa (Dusicyon veletus).

A flora compôe-se de coqueiral, restinga, capoeira, plantas hidrófilas, e em alguns trechos encontram-se orquídeas (Resolução 387/91-CEPRAM).

\section{Localização do Passivo Ambiental}

A ocorrência localiza-se a 700 metros do entroncamento de Guarajuba, no sentido leste em direção ao mar, lado direito da via de acesso a praia. Apresentando aproximadamente $2500 \mathrm{~m}^{2}$ de área totalmente degradada com desmatamento e retirada da vegetação de restinga e adjacentes, destruição da fauna, causado pelo descarte dos resíduos sólidos na forma de "lixão".

Esta área localiza-se na ZONA B, definida pela Resolução 387/91- CEPRAM, sendo vedada nela, quaisquer tipos de ocupação ou interferências antrópicas, tendo como coordenadas centrais, latitude 12ํ3' $57^{\prime \prime}$ e longitude $38^{\circ} 04^{\prime} 24^{\prime \prime}$. 


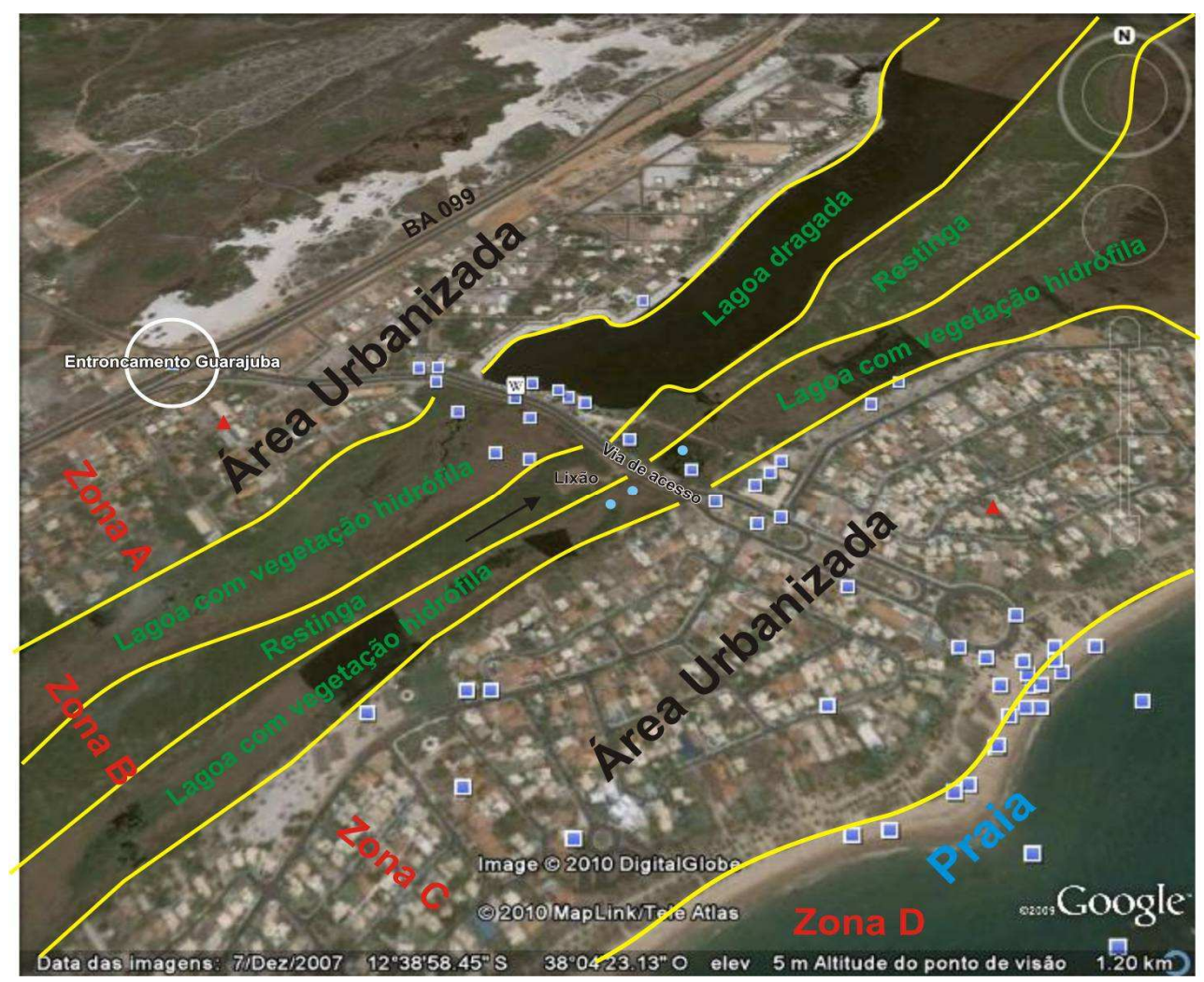

Figura 03 - Imagem aérea da área da ocorrência do passivo com apresentação dos biomas, área urbanizada e o zoneamento determinado pela Resolução 387/91-CEPRAM. Escala aproximada: 1:9.400.

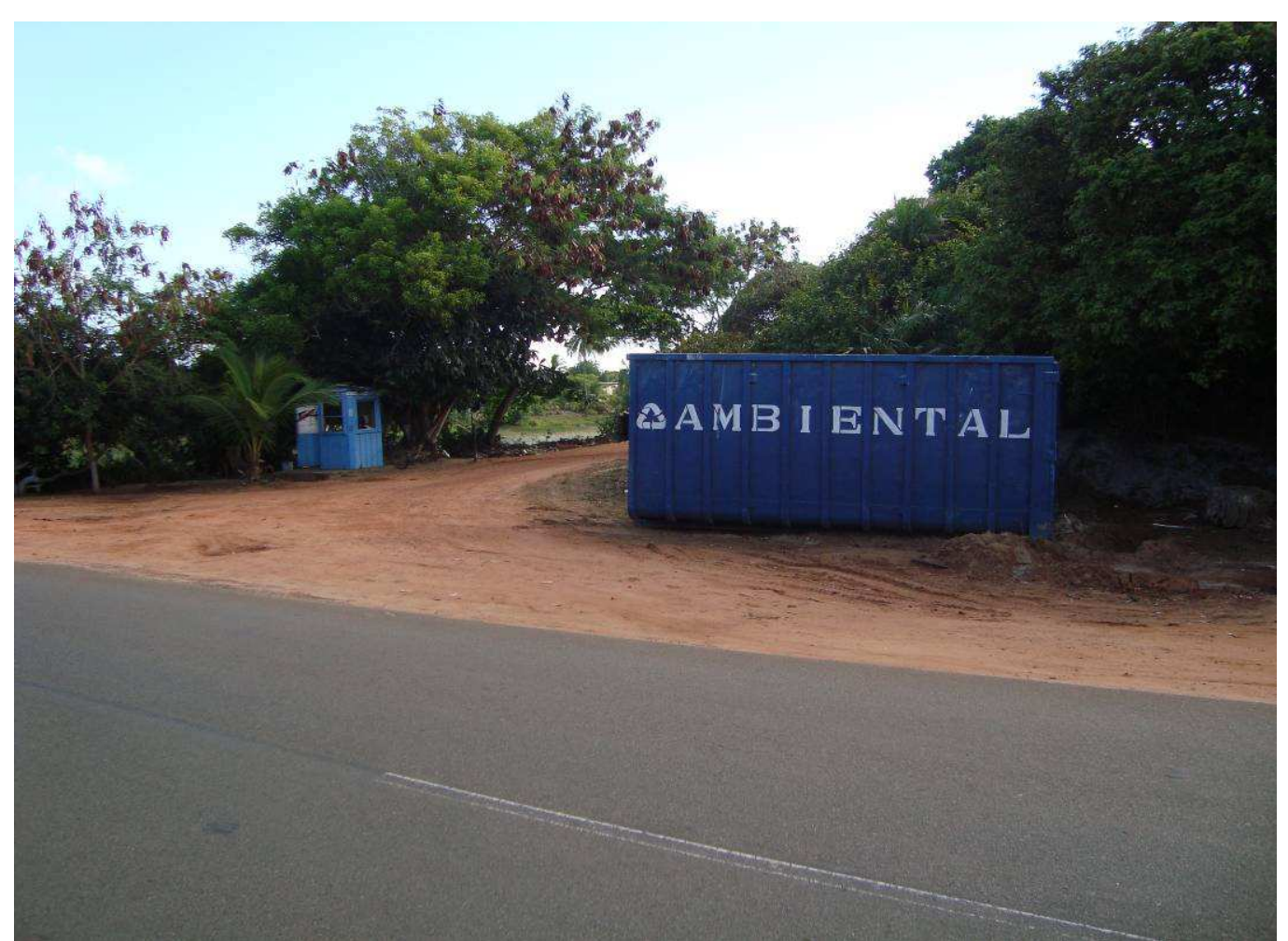


Figura 04 - Entrada de Acesso ao Lixão.

\section{Bioma Atingido e Geologia da Área}

Dentre os principais biomas que compõem a APA, constituída de Lagoas, Áreas úmidas, Manguezais, Dunas, Praias e os Rios Jacuípe e Pojuca, o mais atingido diretamente pela ação antrópica impactante foi a mata de restinga com sua fauna e flora, localizada na zona $\mathrm{B}$, que tem como característica principal, a impossibilidade de haver quaisquer tipo de ocupação urbana, ficando seu uso limitado a atividades de caráter cultural e recreativo (artigo $8^{\circ} \operatorname{Res} 387 / 91$ ). Não obstante, teve parte da vegetação retirada e/ou queimada, formando uma clareira de dimensão já anteriormente mencionada, onde está localizado o lixão.

Do ponto de vista geológico, a região esta sobre os sedimentos eólicos superficiais, caracterizados por dunas estáveis, fazendo parte das formações costeiras de idade terço quarternárias, compostas de arenitos e conglomerados com estratificação cruzada e restos de conchas de animais atuais.

Em alguns casos, há litificação dos sedimentos, resultado da cimentação com material calcífero, proveniente da dissolução do carbonato de cálcio das conchas (beach rock). A sedimentação eólica é identificada como de excelente permeabilidade, pelo alto grau de seleção e uniformidade das areias que compõem as dunas, permitindo assim, grande transmissividade de líquidos.

\section{Hidrogeoquímica de Zona Costeira}

A composição química da água de chuva, normalmente contendo acido carbônico da reação entre o $\mathrm{CO}^{2}$ e $\mathrm{H}^{2} \mathrm{O}$ na atmosfera, é função de sua distancia para o mar e de contaminações naturais e artificiais. 
Normalmente, os sólidos totais dissolvidos ricos em cloro e sódio nessas águas, variam de algumns miligramas por litro em áreas continentais não industrializadas a algumas dezenas de miligramas por litro em áreas costeiras.

"O pH das chuvas em zonas não industrializadas varia entre 5 e $6 . \mathrm{O} p H$ de equilíbrio para água de chuva sem poluição em contato $\mathrm{com} \mathrm{CO}^{2}$ é de 5,7 . Em áreas industriais, o pH é inferior a 5,7, ficando entre 3 e 4" (SILVA, 1984/86, p. 5).

No caso da região estudada, não há indústrias, a vocação da região é turística, portanto as águas pluviais que irão influenciar o ciclo hidrogeológico da área, terão maiores concentrações de sais e pH levemente ácido.

\section{Tipos de Agentes Poluentes no Local}

Em verificação feita in loco, foram encontrados na área do lixão os seguintes materiais discriminados a baixo:

a) Resíduos orgânicos

- restos de alimentos

- folhas

- madeiras

- papeis

b) Resíduos inorgânicos

- latas de cervejas

- vidros

- garrafas Pet

- materiais de construção

c) Lixos tóxicos

- pilhas, pequenas baterias e componentes eletrônicos de celular - tintas

d) Materiais Particulados oriundos da queima dos resíduos 


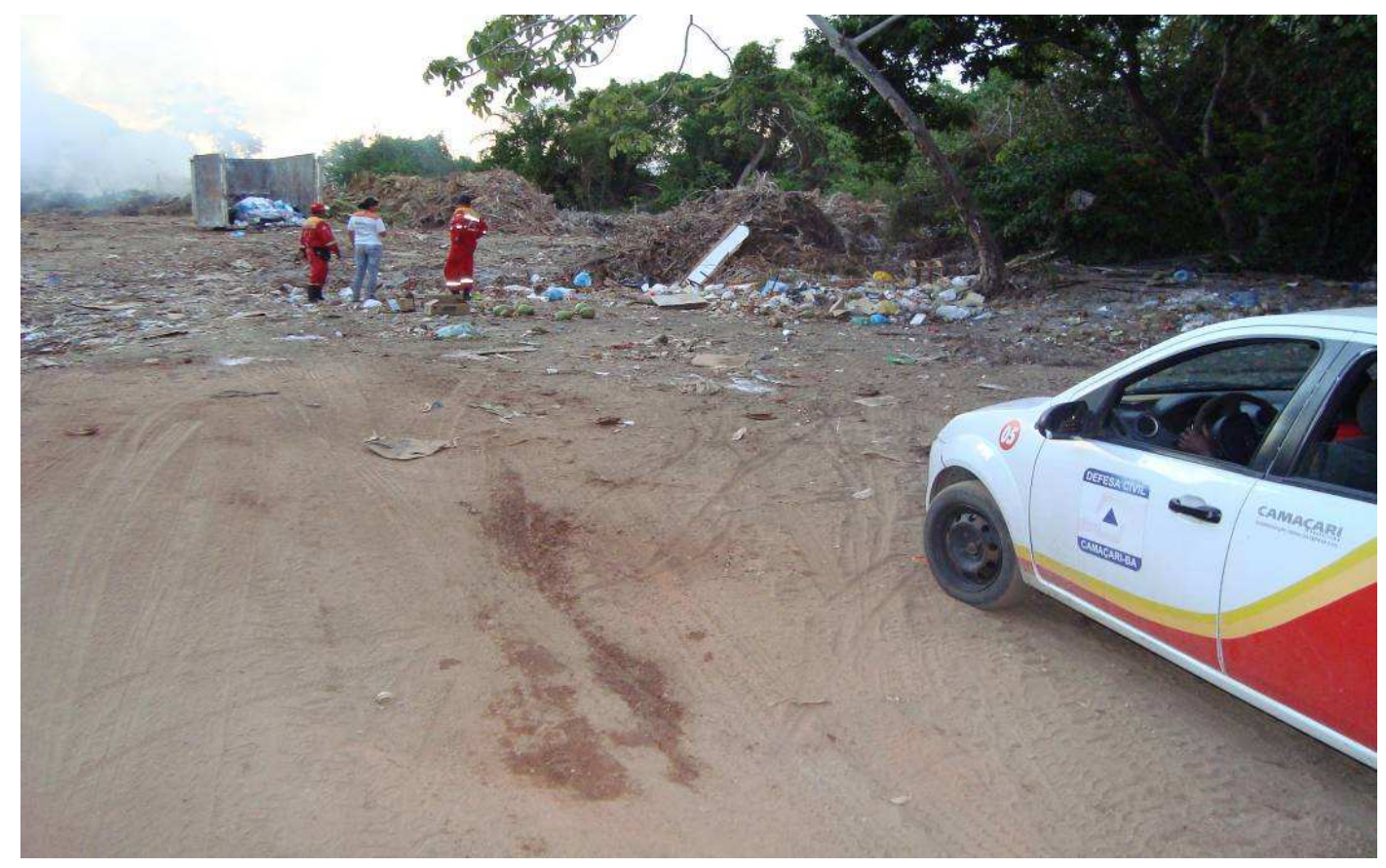

Figura 05 - Conivência da Prefeitura de Camaçari, com funcionários acompanhando o descarte e queima dos resíduos.

\section{Principais Ações Impactantes Ocorridas}

Principais externalidades impactantes, que geraram o passivo em estudo:

1) Desmatamento da vegetação $\left(\mathrm{m}^{2} \mathrm{e} \mathrm{Kg}\right)$;

2) Disseminação do material particulado com a queima dos resíduos $\left(\mathrm{m}^{2}\right)$;

3) Contaminação dos lençóis freáticos e subterrâneos com a lixiviação e percolação da água $\left(\mathrm{m}^{3}\right)$;

4) Destruição da fauna e flora local por ação antrópica $(\mathrm{Kg})$;

5) Descarte dos resíduos $(\mathrm{Kg})$;

6) Desfiguração da paisagem natural - área preservação ambiental (APA) $\left(\mathrm{m}^{2}\right)$;

7) Proliferação de insetos, roedores em todo o entorno $(\mathrm{Kg})$; 
8) Emissões atmosféricas, quando da sua queima, produzindo odores e gases e poluentes ambientais $(\mathrm{Kg})$;

9) Aumento de concentração no ar de $\mathrm{CO}$ e $\mathrm{CO}^{2}$, gerados pela queima dos resíduos (ppm).

\section{Análise das Ações Impactantes}

Do diagrama mostrado abaixo, usando as externalidades impactantes numeradas, depreende-se que a ação de origem antrópíca, mais danosa ao meio ambiente deste local, foi o descarte de resíduos, que praticamente foi o principal agente de degradação da área de preservação (Zona B). Também fica evidenciada, a retirada da flora e fauna ali localizada, que foram muito impactados pelo evento do "lixão", possibilitando a proliferação de insetos e roedores nos entornos urbanizados.

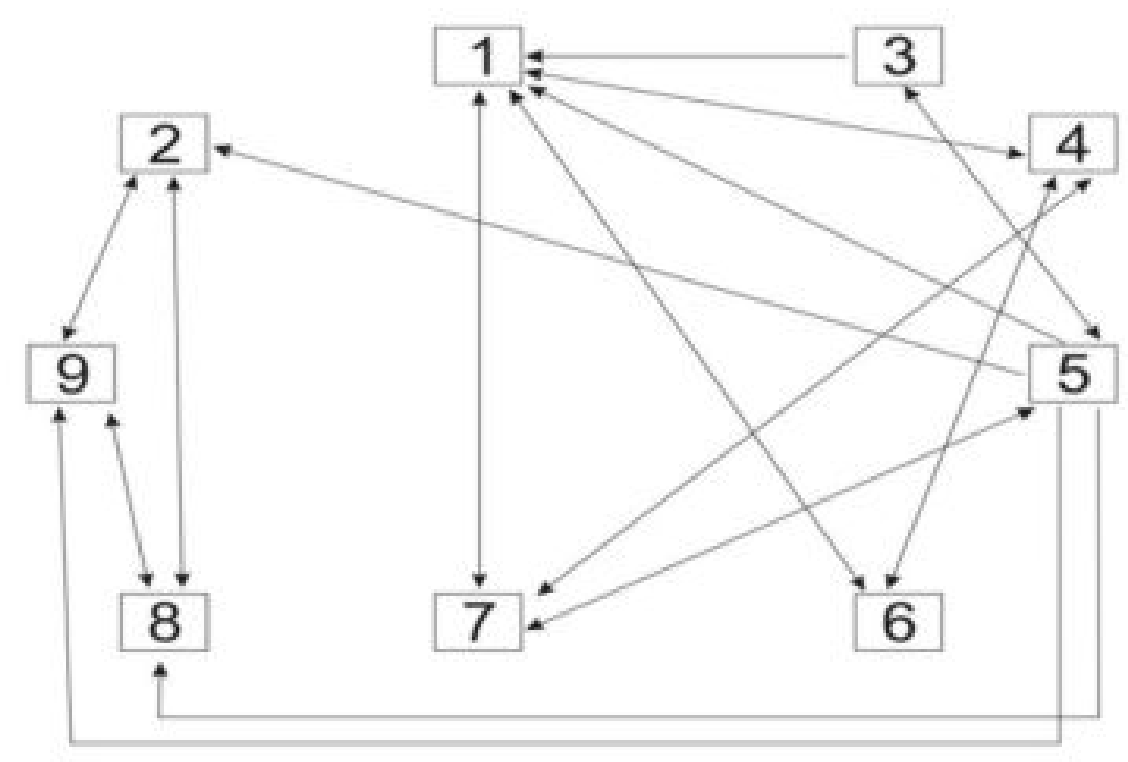

Figura 06 - Diagrama da Rede de Relacionamentos das Externalidades 


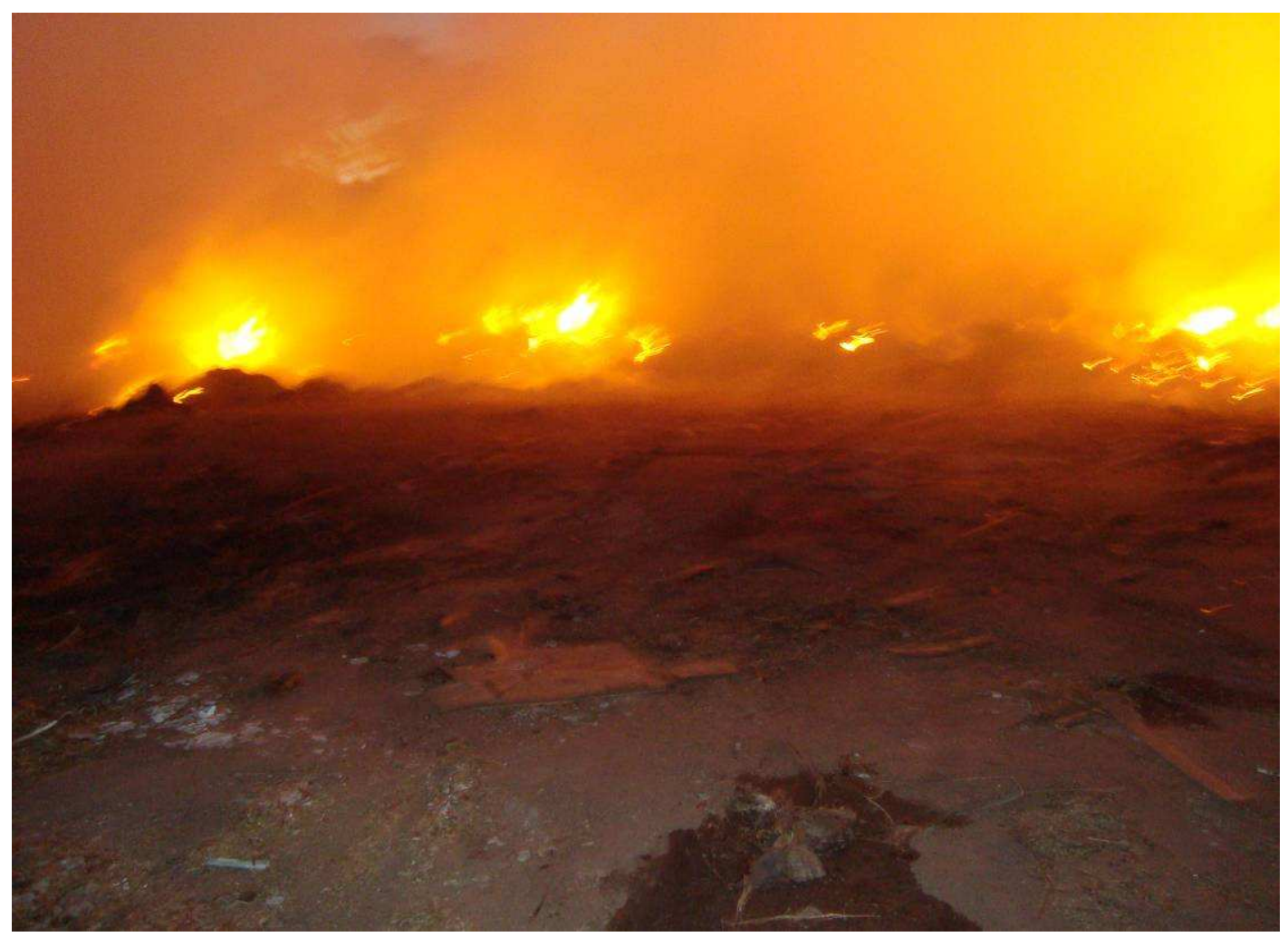

Figura 07 - Emissões atmosféricas, quando da queima dos resíduos, produzindo odores e gases e poluentes ambientais.

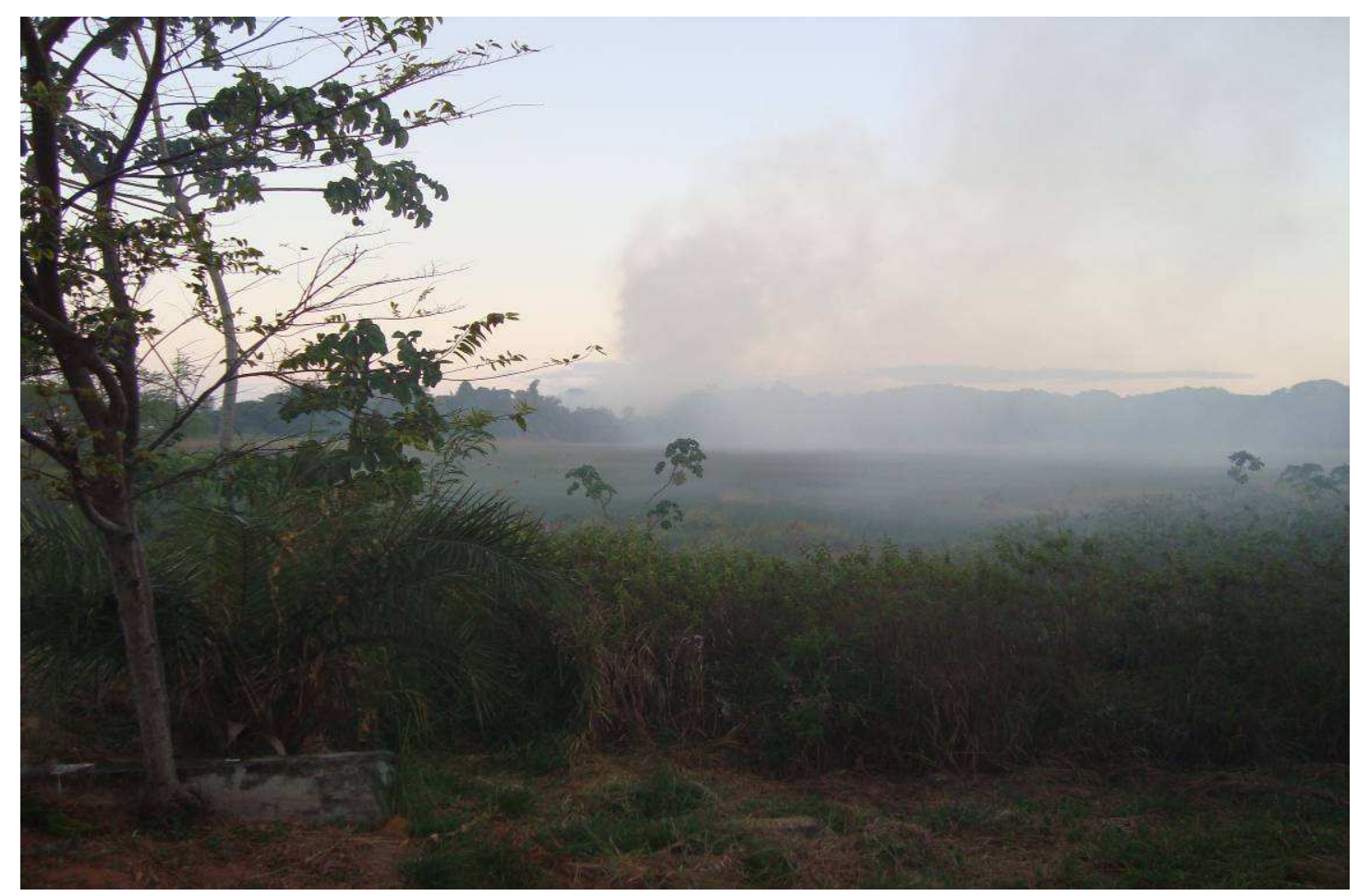


Figura 08 - Disseminação do material particulado com a queima dos resíduos.

\section{Mecanismo e Processo de Poluição}

\section{Fator água e solo}

Pode-se notar, que pelo tipo de resíduos sólidos que são lançados na área em questão, a sua variabilidade, pode produzir lixiviados (chorume) com elevados teores de substâncias e íons de propriedades tóxicas, que são resultantes da decomposição e dissolução das fontes poluidoras lançadas no lixão, como entulhos de construção, latas, tampas de garrafas, embalagens pet, material orgânico, dentre outras.

Estas substâncias dissolvidas se combinam com outras de grande poder de ionização, formando compostos perigosos nocivos a saúde humana, que são lançados nos lençóis freáticos superficiais e subterrâneos, com o escoamento e percolação do lixiviado no solo e subsolo.

Cita-se aqui, algumas fontes de resíduos sólidos e os principais íons liberados pela sua decomposição, possibilitando a formação de compostos poluidores altamente tóxicos, contendo estas substâncias (SILVA, 2002).

Tabela 01 - Fontes poluidoras e íons liberados.

\begin{tabular}{l|l}
\hline FONTES POLUIDORAS & $\begin{array}{l}\text { IONS } \\
\text { LIBERADOS }\end{array}$ \\
\hline Material orgânico, entulhos de construção e cascas de ovos & $\mathrm{Na}+, \mathrm{k}+\mathrm{Ca}^{2} \mathrm{e} \mathrm{Mg}^{2}$ \\
\hline Material orgânico & $\mathrm{PO}^{3}, \mathrm{NO}^{3}, \mathrm{CO}^{2}$ \\
\hline Material eletrônico, latas, tampas de garrafas & $\mathrm{Cu}^{2}, \mathrm{Fe}^{2}$ e $\mathrm{Sn}^{2}$ \\
\hline Pilhas comuns e lampadas florescentes & $\mathrm{Hg}^{2} \mathrm{e} \mathrm{Mn}^{2}$ \\
\hline Baterias recarregáveis & $\mathrm{Ni}^{2}, \mathrm{Cd}^{2}$ e $\mathrm{Pb}^{2}$ \\
\hline
\end{tabular}




\begin{tabular}{l|l} 
Latas descartáveis, cosméticos e embalagens laminadas & $\mathrm{Al}^{3}$ \\
\hline Tubos de PVC & $\mathrm{Cl}-, \mathrm{Br}-, \mathrm{Ag}+$ \\
\hline Embalagens de tintas, vernizes e solventes orgânicos & $\mathrm{As}^{3}, \mathrm{Sb}^{3} \mathrm{e} \mathrm{Cr}^{2}$ \\
\hline
\end{tabular}

\section{Classificação e Avaliação dos Resíduos}

O assunto suscita muitas controvérsias com relação a sua classificação, devido ao enquadramento do tipo de resíduo e quem produziu. Entretanto, a Agência Nacional de Vigilância Sanitária - ANVISA, através da Resolução 33 de fevereiro de 2003, classificou os resíduos em "classes", tendo como parâmetros sua composição segundo as características biológicas, físicas, químicas, estado de matéria e origem. Assim classificados:

Tabela 02 - Classes dos resíduos

\begin{tabular}{|l|l|}
\hline Classe A & $\begin{array}{l}\text { Resíduos potencialmente infectantes - descarte da rede pública } \\
\text { da saúde }\end{array}$ \\
\hline Classe B & Resíduos químicos \\
\hline Classe C & Resíduos radioativos \\
\hline Classe D & Resíduos comuns \\
\hline Classe E & Residuos perfurocortantes \\
\hline
\end{tabular}

Tem-se que mencionar, que as Resoluções Conama 5 e 283, além das NBR's 10.004 e 12808, também usam o sistema de "classes" para enquadrar os resíduos, com destaque para a NBR 10.004, que os discriminou quanto aos riscos ao meio ambiente e à saúde pública.

No caso em tela, o resíduo estaria classificado como de classe " $D$ ", porém, podendo apresentar produtos perigosos, relativo ao descarte de materiais elétrico-eletrônico (pilhas e baterias de celular e etc), restos de tinta e outros, com risco à saude pública, ao meio ambiente, apresentando toxicidade e patogenicidade. Recentemente, foi sancionada a Lei 12.305 de agosto de 2010, que criou a Política 
Nacional de Resíduos Sólidos, incluindo responsabilidades para Estados e Municípios na gestão dos resíduos, e ainda, fez a classificação quanto a origem e periculosidade.

\section{Fator ar}

Com a queima dos resíduos, parte destas substâncias são lançadas no ar como emissões gasosas, que dependendo do seu peso específico, poderão se depositar nas camadas mais superficiais do solo na região, além do material particulado que também se precipita. Outro ponto importante é a emissão de $\mathrm{CO}$ e $\mathrm{CO}^{2}$ na atmosfera, contribuindo de forma inegável com o aumento da temperatura e mudança do microclima da região.

\section{Conseqüências Principais}

Modificação da paisagem natural, observada na dragagem das lagoas, destruição da mata de restinga e vegetação adjacente, da fauna local, para o lançamento dos resíduos. Tendo ainda, como uma das principais conseqüências, a contaminação das lagoas na superfície e dos reservatórios freáticos subterrâneos, por substâncias perigosas e nocivas presentes nos compostos resultantes da decomposição de materiais orgânicos e inorgânicos, podendo causar carcinogênese e envenenamento na população circulante, aumento de insetos e roedores indesejáveis nas residências e hotéis, favorecendo o aparecimento de endemias. Além da presença de material particulado, oriundo da queima dos resíduos, patrocinando aumento da possibilidade de doenças respiratórias.

A região de Guarajuba tem grande vocação turística, entretanto, continuando estas ações poluidoras e danosas ao meio ambiente, poderá haver uma diminuição do fluxo turístico, com reflexo negativo na economia local.

\section{Possibilidades de Amostragem e Priorização de Análises Laboratoriais}


Fazer análises químicas, visando detectar os compostos esperados nas etapas de avaliações preliminares, para verificação de suas concentrações, comparando os resultados com os parâmetros destes elementos encontrados na natureza. Se formos fazer amostragem do ar, as amostras devem ser coletadas a NE na região mais densamente povoada e a SW da ocorrência do passivo para observar a qualidade do ar, evidenciando concentrações de $\mathrm{CO}$ e $\mathrm{CO}^{2}$, no momento da queima dos resíduos, porque a direção do vento preferencialmente durante o ano, é no sentido NE - SW. As amostras de água devem ser coletadas no setor da lagoa a leste $(E)$ do passivo, devido ao fluxo hidrodinâmico das águas de superfície e subterrâneas, ser em direção e sentido para o oceano.

De acordo com Costa Junior (1998), em sua Dissertação de Mestrado, encontrou nas análises químicas de água superficial e subterrânea da área de Guarajuba, concentrações de 69,35 mg/l de N-NO3 (nitrato), 70,08 mg/l de N-NH3 (amônia), indicadores de contaminação por esgotos. Também detectou alta concentração de fosforo inorgânico 4,66 mg/l de P-PO4 e ainda, que o pH era redutor, refletindo maior disponibilidade de matéria orgânica e alta atividade bacteriana.

Tem-se a mencionar, outros parâmetros inorgânicos, que devem ser considerados e analisados, devido a formação de lixiviados, resultado da decomposição e dissolução dos resíduos inorgânicos, já discriminados anteriormente. Será esperado, pelos valores dos parâmetros medidos no trabalho mencionado acima, que se formos analizar o parâmetro DBO, os valores medidos estarão bem acima dos encontrados para águas não poluídas, devido à degradação da matéria orgânica feita por bactérias aeróbias, favorecendo a presença de vegetação hidrófila (algas), que sobrevivem em ambientes com pouco oxigênio.

\section{Parâmetros Legais para os Fatores Ambientais Ar e Água}

Sobre a água, a Resolução Conama 357/2000, define as condições de uso com relação a sua aplicação, como a área em estudo tem vocação turística, o consumo 
humano tem que ser considerado, neste caso, ela tem ser classificada como doce e de classe especial, e ainda, atender o disposto na Portaria Conama 518/2004, que define potabilidade. Na localidade também, parte da lagoa que foi dragada, é usada para esporte náutico e laser, tendo que se considerar então, a Resolução Conama 274/2000, que define parâmetros de balneabilidade.

A qualidade do ar esta determinada nos parâmetros da Resolução Conama 05/89 ou Resolução Conama 03/1990, já que na área não se encontram indústrias e/ou outras atividades, que patrocinem emissões gasosas, salvo a ação de degradação aqui mencionada.

\section{Técnicas utilizadas}

Este trabalho foi respaldado pelas ciências cartográficas com apresentação de mapas, geologia descrevendo o tipo litológico e suas características, geografia econômica, evidenciando situação da região espacial e suas implicações sócioeconômicas, química descritiva com citação da decomposição de determinados materiais já mencionados em outros estudos técnicos, biológicos com descrição dos biomas encontrados na descrição da APA, legais, confrontando a situação encontrada do passivo com a Resolução CEPRAN 387 e matemática, calculando o volume de lixo diário da localidade em estudo, fotográfica com exposição das fotos da área adjacente e da ocorrência do passivo e "Ad Hoc" com verificação da situação e características feita no local.

\section{REVISÃO BIBLIGRÁFICA E EPISTEMOLOGIA}

Todo este trabalho foi pautado nos conteúdos pertinentes a cada respectivo assunto, contidos nas obras aqui mencionadas, com ênfase na gestão de resíduos sólidos, citamos as obras Almeida J. R., Gestão Ambiental, Almeida J. R., Perícia Ambiental Judicial e Securitária, Ribeiro D. V. et al, Resíduos Sólidos problema ou 
oportunidade e Sánches L. E., Avaliação de Impacto Ambiental, que foram os pilares do nosso embasamento técnico neste estudo.

\section{DISCUSSÃO E RESULTADOS}

O que ficou absolutamente claro nesta avaliação, foi o aumento da expansão urbana desorganizada naquela área. Este fator tem promovido um aumento significativo na produção de resíduos sólidos, que estão sendo descartados em setor inadequado e proibido dentro da APA. Por se tratar de região com grande vocação turística e de concentração urbana com alto poder aquisitivo, observamos que o tipo de resíduos sólidos, são característicos desta faixa da população e região.

Conforme mostrado em fotografias, foram encontrado resíduos de restos de construção, de material elétrico e eletrônico descartável, restos de latas de alumínio e ferro, restos de utensílios de maquiagem e matéria orgânica dos restos de alimentos, palhas de coqueiros e da vegetação dos arredores. De acordo com Costa Junior (1998), foi encontrado na região teores de 69,35 mg / I de N-NO3 e 70,08 mg / I de $\mathrm{N}_{-} \mathrm{NH}^{3}$, e 4,66 mg / I de P-PO4, indicando descarga de esgoto e matéria orgânica no lençol freático. Entretanto, poder-se-ia fazer também, análises químicas para verificação de teores de íons de $\mathrm{K}, \mathrm{Mg}, \mathrm{Cu}, \mathrm{Fe}, \mathrm{Sn}, \mathrm{Ni}, \mathrm{Cd}, \mathrm{Pb}, \mathrm{Cl}, \mathrm{Br}, \mathrm{Ag}, \mathrm{As}$, $\mathrm{Sb}$ e $\mathrm{Cr}$, que possivelmente podem ser formados pela decomposição dos resíduos sólidos descartados na área do "lixão, conforme indica Silva (2002). Não foram feitos ensaios neste sentido, devido ao alto custo e falta de logística para este trabalho.

A média brasileira de produção de massa de resíduos sólidos é de aproximadamente $700 \mathrm{~g} / \mathrm{hab} / \mathrm{dia}$, Rocha et. al. (2009).

O que torna este trabalho interessante, é que possibilita indicação para novas avaliações, sobre os teores dos elementos químicos e íons acima mencionados em pesquisas futuras. Muitos deles apresentam toxidade e são nocivos a saúde humana 
quando se combinam, como é o caso dos elementos $\mathrm{Pb}, \mathrm{As}, \mathrm{Cr}, \mathrm{Mg}, \mathrm{Sb}$ e $\mathrm{Cd}$. Permite além do disposto acima, que interessados possam cobrar dos Poderes Públicos solução para o cumprimento da legislação.

$\mathrm{Na}$ gestão de áreas turísticas, devem ser evitados projetos que: Eliminem ou coloquem em risco ecossistemas que por seu valor ambiental devem ser protegidos, como mangues, restingas, dunas, recifes, corais, falésias, floresta atlântica, dentre outros de comprovada importância e fragilidade ambiental, e também, que não apresentem ações concretas para o correto tratamento e disposição de resíduos sólidos e esgotos, assim como o planejamento adequado da infraestrutura básica, com estradas, redes de energia e etc, Almeida (2008a).

Quando determinadas ações necessárias a proteção e preservação de áreas ambientais deixam de ser tomadas, ocorrem fatores negativos, a degradação, fruto da ocupação desordenada do solo, como é o caso do "lixão", dento da APA Lagoas de Guarajuba.

\section{PROPOSTA DE SOLUÇÃO MITIGADORA}

Seria suspender imediatamente o descarte e a queima dos resíduos sólidos, lançando-os em local adequado e reflorestar com mudas vegetais próprias da mata degradada de restinga.

No caso dos compostos solúveis que passaram para os aqüíferos superficiais e subterrâneos, esperar a diluição natural e capacidade da natureza se recuperar no tempo (resiliência). 
Como alternativa para solucionar o problema do resíduo produzido no local, os mesmos poderão ser dispostos em aterro sanitário simplificado que hoje tem seus procedimentos disciplinados pela Resolução Conama 404 de 2008.

Esta nova concepção de aterro já existe e vem sendo utilizada em outros municípios na Bahia. Criado pela Companhia de Desenvolvimento Urbano do Estado da Bahia Conder, para atender aos municípios com população inferior a 15 mil habitantes, podendo neste caso, a partir de estudo e avaliação, ser determinada área próxima para a construção deste tipo de aterro, dando destinação adequada aos resíduos sólidos, gerados na localidade de Guarajuba.

O aterro sanitário simplificado proposto pela Conder é um projeto modular, cujos impactos negativos causados ao meio ambiente com a sua implantação são inexpressivos e de fácil controle, comparado com os benefícios, que o mesmo é capaz de proporcionar aos municípios que se utilizam deste sistema.

O lixiviado, por exemplo, é tratado através da infiltração natural do solo, em tempos chuvosos, as águas coletadas na área do aterro através do sistema de drenagem superficial, são conduzidas diretamente para os cursos d'água, com a finalidade de evitar que o fluxo atinja as valas de aterramento do lixo.

As águas que por ventura atingirem diretamente a vala, não deverão transforma-se em lixiviado. Para tanto, o resíduo estará recoberto com solo ou manta plástica, evitando o contato. A água que ficar acumulada na vala será bombeada para outra vala, que já deverá estar pronta.

A prática de cobrir os resíduos diariamente com uma camada de solo de espessura de 0,15 a $0,20 \mathrm{~m}$, torna possível a diminuição da proliferação de vetores de doenças (moscas, ratos, mosquitos e baratas), e reduz a produção dos gases (Metano-CH4, Dióxido de Carbono-CO2, Acido Sulfúrico-H2S, AmôniaNh3), gerados na decomposição da matéria orgânica pelos microorganismos, não 
havendo necessidade do dreno vertical, minimizando ainda mais os custos (CONDER, 2002).

\section{AÇÃO AMBIENTAL GOVERNAMENTAL E ARRECADAÇÃO TRIBUTÁRIA}

Muitos municípios adotaram o Programa de Avaliação e Desenvolvimento Fazendário - PADF, visando otimizar a busca de recursos financeiros tributários e melhorar a performance administrativa da arrecadação municipal.Tendo em vista este fato, aparece o fator ambiental indo ao encontro desta nova política, que muitos destes entes da Federação consideram um fardo, porque estão obrigados pela Constituição Federal a manter e preservar o patrimônio cultural e ambiental, sem que nenhuma contrapartida financeira seja concedida, pelos outros membros federativos de maior porte.

Então, em meio a este cenário, coadunando-se nesta nova visão administrativa, aparece o conceito do "ICMS VERDE", Constituindo-se em incentivo financeiro dado pelos Estados aos municípios, que compôem respectivamente, as suas bases territoriais, para que eles recebam uma cota parte do valor arrecadado de ICMS, pela ação ambiental e cultural de preservação das suas unidades de conservação, conforme Lei 9985 de 2000 (Lei do SNUC).

O mecanismo de distribuição efetiva-se da seguinte forma:

A Constituição Federal, no capítulo da repartição das receitas, determina que $25 \%$ (vinte e cinco) do arrecadado pelos estados na rubrica ICMS, sejam distribuídos para os municípios da sua base territorial, atendendo ao seguinte:

Do montante determinado constitucionalmente, $3 / 4$ ou $75 \%$, vai de forma obrigatória para o município respectivo, obedecendo ao critério do valor adicionado, calculados pelos Tribunais de Contas e até $1 / 4$ ou $25 \%$ do saldo restante o Estado distribui de 
forma discricionária. É deste valor distribuído pelo Estado, que pode ser criado o "ICMS VERDE" através de Lei Estadual, determinando a alíquota e os critérios de distribuição para os municípios.

Vale ressaltar, que os valores arrecadados com o ICMS Verde, não estão vinculados, o administrador municipal pode dispor livremente dos recursos para aplicar de acordo com suas programações e projetos de governo.

Dos 26 estados da Federação, 13 tem instituídos o "ICMS VERDE", como mostramos na tabela, com as respectivas legislações, alíquotas e critérios de distribuição.

Tabela 03 - Estados da federação que têm instituído o "ICMS VERDE".

\begin{tabular}{|c|c|c|c|}
\hline Estado & Legislação (Obs.:) & $\%$ & $\begin{array}{l}\text { Critérios para Receber o ICMS } \\
\text { Ecológico (\% do ICMS Ecológico } \\
\text { por critério) }\end{array}$ \\
\hline Para & $\begin{array}{lr}\text { LC n. 59/91; Decreto } \\
\text { Estadual } & \text { N.o } \\
2.791 / 96 & \text { Decreto } \\
\text { Estadual } & \text { N.o } \\
3.446 / 97 & \text { Decreto } \\
\text { Estadual } & \text { N.o } \\
1.529 / 07 & \text { Resoluções } \\
\text { da SEMA } & \end{array}$ & $5 \%$ & $\begin{array}{l}\text { Municípios que possuem Mananciais } \\
\text { Municípios que possuem Unidades de } \\
\text { Conservação Municipais, Estaduais e } \\
\text { Federais, Áreas Indígenas, Faxinais, } \\
\text { RPPN`s Áreas de Preservação } \\
\text { Permanente e/ou Reserva Legal } \\
(2,5 \%)\end{array}$ \\
\hline $\begin{array}{l}\text { Minas } \\
\text { Gerais }\end{array}$ & $\begin{array}{l}\text { Lei Estadual N.o } \\
12.040 / 95 \text { (Lei Robin } \\
\text { Hood) revogada pela } \\
\text { Lei Estadual N. o } \\
13.803 / 00\end{array}$ & $1 \%$ & $\begin{array}{l}\text { IC - Índice de Conservação - } \\
\text { referente a unidades de conservação e } \\
\text { ISA - Índice de Saneamento } \\
\text { Ambiental - referente a aterros } \\
\text { sanitários, estação de tratamento de } \\
\text { esgoto e usinas de compostagem } \\
(0,5 \%)\end{array}$ \\
\hline
\end{tabular}




\begin{tabular}{|c|c|c|c|}
\hline $\begin{array}{l}\text { São } \\
\text { Paulo }\end{array}$ & $\begin{array}{l}\text { Lei Estadual N.o } \\
8.510 / 93\end{array}$ & $0,5 \%$ & $\begin{array}{l}\text { Áreas Especialmente protegidas } \\
(0,5 \%) \text { (Recebem o benefício apenas } \\
\text { Unidades de Conservação Estaduais) }\end{array}$ \\
\hline $\begin{array}{l}\text { Rio de } \\
\text { Janeiro }\end{array}$ & $\begin{array}{l}\text { LE n. 2.664/96; LE n. } \\
5.100 / 07\end{array}$ & $\begin{array}{l}1 \% \\
(\mathrm{em} \\
2009 \\
)\end{array}$ & $\begin{array}{l}\text { Unidades de Conservação }(0,45 \% \text {, } \\
\text { sendo que as prefeituras que criarem } \\
\text { Qualidade da áqua }(0.30 \%) \\
\text { Administração dos Resíduos Sólidos } \\
(0,25 \%)\end{array}$ \\
\hline \multirow{3}{*}{$\begin{array}{l}\text { Pernamb } \\
\text { uco }\end{array}$} & \multirow{3}{*}{$\begin{array}{lr}\text { Lei Estadual } & \text { N.o } \\
11.899 / 00 \quad \text { (neste } \\
\text { Estado o imposto é } \\
\text { denominado ro } \\
\text { "ICMS } & \text { Sócio- } \\
\text { ambiental") } & \end{array}$} & \multirow[t]{3}{*}{$15 \%$} & Unidades \\
\hline & & & $\begin{array}{l}\text { Usinas de Compostagem e Aterro } \\
\text { Desempenho na Área de Educação - } \\
\text { de acordo com o número de alunos } \\
\text { Desempenho na área de saúde - }\end{array}$ \\
\hline & & & $\begin{array}{l}\text { De acordo com a Receita Tributária } \\
\text { própria do Município }(3 \%)\end{array}$ \\
\hline $\begin{array}{l}\text { Mato } \\
\text { Grosso }\end{array}$ & $\begin{array}{l}\text { LC n.73/00; } \quad \text { DE } \\
\text { n. } 2.758 / 01 \quad \text { LC } \\
157 / 04\end{array}$ & $5 \%$ & $\begin{array}{l}\text { Unidades de Conservação e Terras } \\
\text { Indígenas (5\%) }\end{array}$ \\
\hline $\begin{array}{l}\text { Mato } \\
\text { Grosso } \\
\text { do Sul }\end{array}$ & 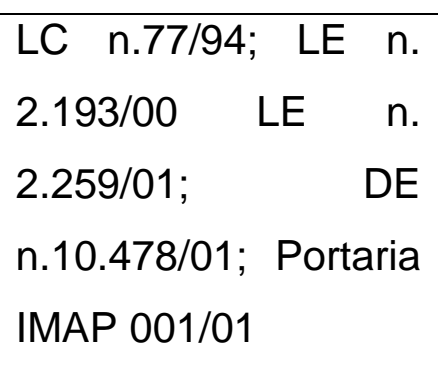 & $5 \%$ & $\begin{array}{l}\text { Unidades de Conservação municipais, } \\
\text { estaduais e federais (incluindo o } \\
\text { entorno), terras indígenas e áreas com } \\
\text { mananciais de abastecimento público } \\
(5 \%)\end{array}$ \\
\hline Amapá & $\begin{array}{l}\text { Lei Estadual N.o } \\
322 / 96\end{array}$ & 1,4 & $\begin{array}{l}\text { Índice de Conservação do Município - } \\
\text { baseado nas unidades de conservação } \\
\text { estaduais, municipais ou federais e } \\
\text { particulares }\end{array}$ \\
\hline $\begin{array}{l}\text { Rio } \\
\text { Grande } \\
\text { do Sul }\end{array}$ & $\begin{array}{l}\text { Lei Estadual N.o } \\
11.038 / 97\end{array}$ & $7 \%$ & $\begin{array}{l}\text { Áreas de Preservação Ambiental e } \\
\text { aquelas inundadas por barragens } \\
\text { exceto aquelas localizadas no } \\
\text { município sede de usinas hidrelétricas }\end{array}$ \\
\hline
\end{tabular}




\begin{tabular}{|c|c|c|c|}
\hline & & & $\begin{array}{l}\text { (7\% - é feita uma relação entre a área } \\
\text { dos municípios e as áreas de } \\
\text { preservação multiplicadas por } 3 \text { ) }\end{array}$ \\
\hline \multirow[t]{4}{*}{ Tocantins } & \multirow{2}{*}{$\begin{array}{l}\text { Lei Estadual N.o } \\
\text { 1.323/02 Decreto Est. }\end{array}$} & \multirow[t]{4}{*}{$13 \%$} & Política Municipal de Meio Ambiente \\
\hline & & & Unidades de Conservação e Terras \\
\hline & & & Controle de queimadas e combate a \\
\hline & $\begin{array}{l}\text { Resolução COEMA } \\
\text { N.o 02/03 }\end{array}$ & & $\begin{array}{l}\text { Conservacão dos Solos }(2 \%) \\
\text { Saneamento Básico e Conservação da } \\
\text { Água }(3,5 \%)\end{array}$ \\
\hline Acre & $\begin{array}{l}\text { Lei Estadual N.o } \\
1.530 / 04\end{array}$ & $5 \%$ & $\begin{array}{l}\text { Unidades de Conservação e áreas } \\
\text { afetadas por elas (entorno) }(5 \%)\end{array}$ \\
\hline Ceará & $\begin{array}{l}\text { Lei Estadual N.o } \\
14.023 / 07\end{array}$ & $2 \%$ & $\begin{array}{l}\text { Índice Municipal de Qualidade do Meio } \\
\text { Ambiente }(2,5 \%)\end{array}$ \\
\hline Rondônia & 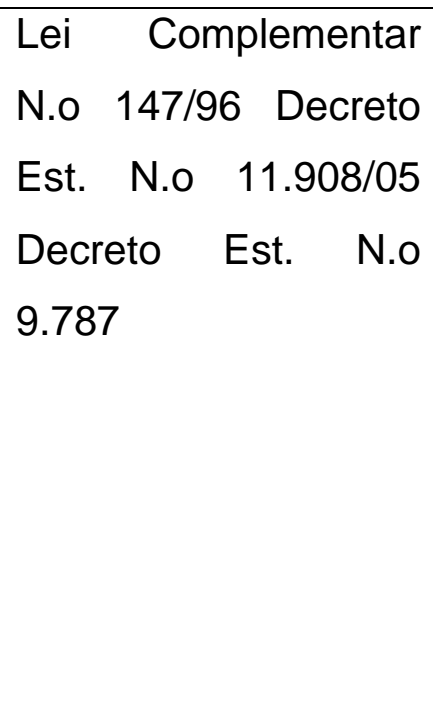 & $5 \%$ & $\begin{array}{l}\text { Unidade de Conservação federal, } \\
\text { estadual ou municipal e terras } \\
\text { indígenas (5\%) - divide-se o total das } \\
\text { áreas de UC dentro do município (em } \\
\text { hectares) pelo valor total das áreas de } \\
\text { UC dentro do Estado e multiplica-se } \\
\text { por } 5 \% \text {. O resultado é o chamado } \\
\text { Fundo de Participação Municipal que } \\
\text { indica quanto o município irá arrecadar } \\
\text { do ICMS Ecológico. }\end{array}$ \\
\hline
\end{tabular}

Finalizando esta análise, ações governamentais desta natureza, poderão contribuir de forma decisiva, para que as administrações municipais, consigam recursos financeiros para gerenciar e manter o seu patrimônio cultural e ambiental. 
A intensa atividade urbana desorganizada, desenvolvida naquela localidade, potencializa a vulnerabilidade do ambiente natural, com a desfiguração da APA Lagoas de Guarajuba, decorrente das contaminações diretas e ou indiretas, geradas pelo descarte de resíduos sólidos na forma de lixão em área inapropriada, já mencionado neste trabalho. Prejudicando de sobremaneira, o meio ambiente natural, a população usuária e o turismo da região. Vale lembrar, que esta ocorrência, pode ser tipificada como crime ambiental, definida na Lei 9.605 de1998, suscitando ações judiciais intentadas pela sociedade civil e ou pelos Ministérios Públicos Federal e ou Estadual.

É possível esperar, que pela grande exploração imobiliária da localidade de Guarajuba, como também, pela inércia dos poderes públicos Municipal e Estadual, no que tange a agir e fiscalizar o cumprimento da legislação ambiental, esta região irá sofrer influencias negativas, causadas pela ocupação urbana desordenada e especulação imobiliária, como de fato já esta ocorrendo. Portanto, o Poder Público deve atuar para disciplinar a ocupação urbana e fazer cumprir as Leis ambientais, permitindo o desenvolvimento econômico com sustentabilidade ambiental.

\section{REFERÊNCIA}

ALMEIDA, J. R. Gestão ambiental. Rio de Janeiro: Thex, 2008a.

Perícia ambiental, judicial e securitária. 2. ed. Rio de Janeiro: Thex, 2008b.

ANTUNES, P.B. Manual de direito ambiental. Rio de Janeiro: Lumen Juris, 2007.

CONDER - Companhia de Desenvolvimento Urbano do Estado da Bahia. Manual de aterro simplificado. Bahia, 2002.

COSTA JUNIOR, O. S. Efeito da percolação de água do lençol freático na região de recifes de coral do litoral norte do estado da Bahia. Dissertação de Mestrado, Universidade Federal da Bahia - UFBA, 1998. 
FARIA, Caroline. ICMS ecológico. Disponível em: <http://www.infoescola.com/ ecologia/icms-ecologico/> Acesso em: 18 ago. 2010.

GUERRA, A. T. Introdução a geomorfologia. 3. ed. Rio de Janeiro: Bertrand Brasil, 1960.

LAHEE, F. H. Geología prática. 4. ed. Barcelona - Espanha: Ediciones Omega, 1975.

SÁNCHEZ, L. E. Avaliação de Impacto Ambiental. 2. ed. São Paulo: Oficina de Textos, 2010.

Zylbersztajn D, Lins C. Sustentabilidade e Geração de Valor. Rio de janeiro: Elsevier, 2010.

LIMA, L. M. Q. Tratamento de lixo. 2. ed. São Paulo: Hemus, 1991.

RIBEIRO, D. V; MORRELI M. R. Resíduos sólidos problema ou oportunidade. Rio de Janeiro: Interciência, 2009.

ROCHA, J.C; ROSA, A.H; CARDOSO, A.A. Introdução à química ambiental. 2. ed. Rio Grande do Sul e São Paulo: Artmed, 2009.

SECRETARIA DE MINAS E ENERGIA, SME. Texto explicativo para o mapa geológico. Estado da Bahia, 1978, p. 55.

SILVA, A. B. Evolução química das águas subterrâneas. Revista Águas Subterrâneas. vol. 7. Associação Brasileira de Água Subterrânea - ABAS, biênio 1982 a 1984, p. 05.

SILVA, A. C. Tratamento do percolado de aterro sanitário e avaliação da toxicidade do efluente bruto e tratado. Universidade Federal do Rio de Janeiro, 2002. (dissertação de mestrado) 